\title{
Efectos de aditivos y levadura en el incremento de peso en terneras holstein-friesian, de tres a seis meses de edad. Tumbaco, Pichincha
}

\section{Effects of additives and yeast in increasing weight in calf Hols- tein-friesian, three to six months old. Tumbaco, Pichincha}

\author{
Eloy Castro Muñoz ${ }^{1}$, Juan Burgos ${ }^{1}$, Juan Pazmiñoํㅜ Luis Valarezo \\ ${ }^{l}$ Universidad Central del Ecuador. Facultad de Ciencias Agrícolas. Jerónimo Leiton y Av. La Gasca s/n. Ciudadela Universitaria. 170521 \\ Quito, Ecuador
}

\begin{abstract}
Resumen
En la localidad de Tumbaco, Pichincha, se evaluó el sistema de suplementación con levadura y los aditivos "Roughage Mate" y "3 Nitro-20", a terneras Holstein-Friesian que, en promedio, pesaban 90 kg y tenían de 3 a 6 meses de edad. El objetivo de este estudio fue evaluar el efecto de los aditivos alimenticios y levadura en el crecimiento y condición corporal de los animales. Para esto se utilizó un diseño completamente al azar con cuatro observaciones y una unidad experimental que estuvo constituida por una ternera. Las variables evaluadas fueron: incremento de peso, condición corporal, incremento de cinchera, altura a la cruz. Los resultandos indican que el mejor tratamiento fue el aditivo "3 Nitro-20", que alcanzó un aumento de peso de 0.80 $\mathrm{kg} /$ ternera/día, un incremento de cinchera de $0.24 \mathrm{~cm} /$ ternera/día y una altura a la cruz de $11 \mathrm{~cm} /$ ternera/día; mientras que para condición corporal la mejor calificación fue de 2.75 .
\end{abstract}

Palabras clave: suplementación, crecimiento, ternera, peso, crecimiento, condición corporal.

\begin{abstract}
In the town of Tumbaco-Pichincha, a supplementation system using yeast and "Roughage Mate" "3 Nitro-20" was evaluated in calves Holstein-Friesian, weighing, in average, $90 \mathrm{~kg} 3$ to 6 months old. The objective of this study was to evaluate the effect of food additives and yeast on growth and body condition of the animals. We used a completely randomized design with four observations and one experimental unit consisting on a calf. The variables evaluated were: weight gain, body condition, increased and wither height. The results indicate that the best treatment was that of additive March 20 Nitro, with which calves reached a weight gain of $0.80 \mathrm{~kg} / \mathrm{calf} /$ day, an increase of girthplace $0.24 \mathrm{~cm} /$ calf / day and wither height of $11 \mathrm{~cm} /$ calf / day; while the best body condition score was 2.75 .
\end{abstract}

Keywords: supplementation, animal growth, calf, weight, growth, body condition.

\section{Introducción}

La crianza de terneras de leche en la Región Interandina de Ecuador, es probablemente la fase más crítica, costosa y determinante del futuro de una explotación ganadera. Ciertos índices productivos registrados en la ganadería bovina de leche en la Sierra del Ecuador como: tasa de mortalidad de terneros (18 al 28\%), destete efectivo (84\%), uso extensivo de leche (1 a 6 litros/ternero/día en períodos de hasta 6 meses), baja tasa de crecimiento y por lo tanto, excesiva edad al primer servicio (24 meses en promedio) muestran y de manera general, una baja eficiencia en la crianza de terneras (Grijalva, 1992).

Los cultivos de levaduras vivas promueven un ambiente más saludable en el rumen, reducien- 
do los niveles de oxígeno y estimulando el crecimiento de bacterias, principalmente de aquellas que degradan las fibras consumen ácido láctico (Amaury, 2011). Los aditivos pueden mejorar la conversión alimenticia, la producción (aumento de peso / leche) y la sanidad, ya que actúan por diferentes mecanismos, incluyendo la modificación de la fermentación ruminal (por aumento de la formación de ácido propiónico disminuyendo la formación de metano y la proteólisis y desanimación de proteínas de la dieta en el rumen), la estabilización del ambiente ruminal y la protección de los patógenos del tracto gastrointestinal (Hillman \& Wells, 2005).

Los estudios realizados si bien han generado resultados importantes han sido dispersos y no se han enfocados en la relación indisoluble entre ganancia de peso y la oportuna incorporación a la reproducción de las terneras, es por ello que el objetivo de esta investigación es demostrar que con la adición de suplementos alimenticios en la dieta se logra aumentar la etapa reproductiva de las vacas productoras de leche.

\section{Materiales y métodos}

El experimento tuvo lugar en los predios del Campo Docente Experimental "la Tola"-CADET, a 2,430 m.s.n.m. y con una precipitación anual de $817 \mathrm{~mm}$ al año se evaluó el sistema de suplementación con levadura (Sacharamyces cerevisiae) y aditivos, a fin de determinar el mejor tratamiento en el incremento de peso de las terneras Holstein-Friesian, de 3 a 6 meses de edad del hato ganadero.

La lista de tratamientos utilizados se resume a continuación:

- T0: Sin aditivos $+($ Forraje $6 \mathrm{~kg} /$ ternera/día $)$ + Mezcla Minera 25g + Agua + (Balanceado $0.75 \mathrm{~kg} /$ ternera/día) $+50 \mathrm{~g}$ de jabón cálcico $+15 \mathrm{~g}$ levadura.

- T1: Roughage mate (5g diarios) + (Forraje $6 \mathrm{~kg} /$ ternera/día) + Mezcla Minera $25 \mathrm{~g}+$ Agua + (Balanceado $0.75 \mathrm{~kg} /$ ternera/día $)+50 \mathrm{~g}$ de jabón cálcico $+15 \mathrm{~g}$ levadura.
- $\mathrm{T}_{2}: 3$ NITRO-20 (2g diarios) + (Forraje $6 \mathrm{~kg} /$ ternera/día) + Mezcla Minera $25 \mathrm{~g}+$ Agua + (Balanceado $0.75 \mathrm{~kg} /$ ternera/día $)+50 \mathrm{~g}$ de jabón cálcico $+15 \mathrm{~g}$ levadura.

Los tratamientos se establecieron por un periodo de 100 días (10 días de adaptación y 90 días para la evaluación), las variables evaluadas fueron: incremento de peso, incremento de cinchera, altura a la cruz, condición corporal y composición botánica de la mezcla forrajera.

Se utilizó un diseño completamente al azar (DCA) con cuatro observaciones y una unidad experimental que estuvo constituida por una ternera, Se estructuraron tres grupos, cada uno conformado por cuatro terneras. En la formación de los grupos se intentó crear grupos homogéneos en términos de edad y peso. Los tratamientos fueron identificados con cabo fórtex de 10 $\mathrm{mm}$ de diferente color ( $\mathrm{T}_{0}$ : verde, $\mathrm{T}_{1}$ : amarillo, $\mathrm{T}_{2}$ azul).

En los tres potreros de corte, se determinó que la mezcla forrajera en su mayoría estaba compuesta por gramíneas invasoras, principalmente kikuyo (Pennisetum clandestinum) y grama común (Cynodon dactylon), debido a su edad ya que tiene más de tres años de siembra.

\section{Resultados y discusión}

\subsection{Incremento de peso}

En el análisis de la varianza para esta variable (Tabla 1) se observa que existen diferencias significativas al $90 \%$ de probabilidad estadística entre tratamientos, con un promedio de incremento de peso de $0.71 \mathrm{~kg} /$ ternera/día y un coeficiente de variación de $14.70 \%$. Se identificaron dos rangos de significancia, en el primero de los cuales se ubicaron el $\mathrm{T}_{2}$ (3-Nitro-20) con un promedio de $0.80 \mathrm{~kg} /$ ternera/ día; en tanto que al final del segundo rango se ubica el $\mathrm{T}_{0}$ ( $\sin$ aditivos) con $0.58 \mathrm{~kg} /$ ternera/día (Tabla 2 ).

Tabla 1. Significancia estadística, para la evaluación de dos aditivos en terneras Holstein-Friesian.

\begin{tabular}{|c|c|c|}
\hline Fuentes de variación & gl & Cuadrados medios \\
\hline Total & 11 & - \\
\hline Tratamientos & 2 & $0.061 *$ \\
\hline Error experimental & 9 & 0.010 \\
\hline $\begin{array}{l}\text { Promedio: } 0.71 \mathrm{~kg} / \text { ternera/día } \\
\text { CV: } 14.70 \%\end{array}$ & & \\
\hline
\end{tabular}


Esta respuesta se debe, probablemente, a que el $\mathrm{T}_{2}$ (3-Nitro-20) fue mejor asimilado por las ternera, (Moromenacho, 2007), debido a la alta concentración de enzimas (roxarsona) que tiene este producto, las cuales ayudan a degradar mejor los alimentos y minimizan los efectos de la coccidiosis.
Araque \& Escalona (2001) indican que con un sistema de crianza que produzca aumentos de peso vivo de 0.50 a $0.75 \mathrm{~kg} /$ día, puede ser razonable, según el sistema de crianza utilizado y el régimen alimenticio.

Tabla 2. Pruebas de Tukey al 5\% para incremento de peso en la evaluación de dos aditivos en terneras Holstein-Friesian.

\begin{tabular}{lc}
\hline \multicolumn{1}{c}{ Tratamientos } & $\begin{array}{c}\text { Promedios de incremento de peso } \\
\mathbf{k g} / \text { ternera/día }\end{array}$ \\
\hline$T 2=$ 3 Nitro-20 (2 g diarios /ternera/ día) & $0.80 \mathrm{a}$ \\
$T 1=$ Roughage mate $(5 \mathrm{~g}$ diarios/ternera/dia $)$ & $0.71 \mathrm{~b}$ \\
$T 0=$ Sin aditivos Testigo absoluto & $0.58 \mathrm{~b}$ \\
\hline
\end{tabular}

\subsection{Incremento de cinchera}

La Tabla 3 muestra que existen diferencias significativas entre tratamientos al $95 \%$ de probabilidad, con un promedio de incremento de cinchera de $0.22 \mathrm{~cm} /$ ternera/día y un coeficiente de variación de $12.03 \%$. Se identificaron dos rangos de significancia, el primero de los cuales incluyó al $\mathrm{T}_{2}$ (3-Nitro-20) con un promedio de $0.24 \mathrm{~cm} /$ ternera/día y al $\mathrm{T}_{1}$ (Roughage mate); en tanto que en el segundo rango se ubicó $\mathrm{T}_{0}(\mathrm{sin}$ aditivos) con $0.18 \mathrm{~cm} /$ ternera/día (Tabla 4 ).
Los resultados alcanzados son superiores a los obtenidos por Moromenacho (2007), quien reportó un incremento de cinchera de $0.19 \mathrm{~cm} /$ ternera/día. Una posible explicación para esta diferencia es que el suministro de levadura mejoró el metabolismo anaerobio o fermentativo, ya que las levaduras son capaces de absorber el oxígeno del rumen, estimulando el crecimiento de las bacterias anaeróbicas, mejorando la producción de ácidos grasos volátiles y regulando el $\mathrm{pH}$, por lo que existe mayor digestibilidad de la fibra de los forrajes, lo cual incrementa la cinchera (Rodríguez, 2012).

Tabla 3. ADEVA para el incremento de cinchera, para la evaluación de dos aditivos en terneras Holstein-Friesian.

\begin{tabular}{lcc}
\hline \multicolumn{1}{c}{ Fuentes de variación } & gl & Cuadrados Medios \\
\hline Total & 11 & - \\
Tratamientos & 2 & $0.007 * *$ \\
Error experimental & 9 & 0.00072 \\
\hline Promedio: $0.22 \mathrm{~cm} /$ ternera/día & & \\
CV: $12.03 \%$ & & \\
\hline Nota: $* * *$ \\
\end{tabular}

Tabla 4. Pruebas de Tukey al 5\% para incremento de cinchera en la evaluación de dos aditivos en terneras Holstein-Friesian.

\begin{tabular}{lc}
\hline \multicolumn{1}{c}{ Tratamientos } & $\begin{array}{c}\text { Promedios de incremento de } \\
\text { cinchera cm/ternera/día }\end{array}$ \\
\hline $\mathrm{T} 2=3$ Nitro-20 $(2 \mathrm{~g}$ diarios /animal/ día $)$ & $0.24 \mathrm{a}$ \\
$\mathrm{T} 1=$ Roughage mate $(5 \mathrm{~g}$ diarios/ternera/día $)$ & $0.24 \mathrm{ab}$ \\
$\mathrm{T} 0=$ Sin aditivos & $0.18 \mathrm{~b}$ \\
\hline
\end{tabular}




\subsection{Altura a la cruz}

El análisis no reporta diferencias significativas entre tratamientos para esta variable (Tabla 5). Una posible explicación para este resultado es ofrecida por Church y Pond (1997), quienes argumentan que el aumento de peso no va necesariamente ligado al crecimiento en altura, pues los animales pueden aumentar de peso en mayor proporción que su altura.

Tabla 5. ADEVA para Altura a la cruz, en la evaluación de dos aditivos en terneras Holstein-Friesian.

\begin{tabular}{lcl}
\hline \multicolumn{1}{c}{ Fuentes de variación } & gl & Cuadrados Medios \\
\hline Total & 11 & - \\
Tratamientos & 2 & 0.000062 \\
Error experimental & 9 & 0.00077 \\
\hline Promedio: $0.11 \mathrm{~cm} /$ ternera/día & & \\
CV: $23.9 \%$ & & \\
\hline
\end{tabular}

\subsection{Condición corporal}

En la Tabla 6, se observa la calificación de Condición Corporal promedio por tratamiento durante el ensayo, ubicándose en primer lugar $\mathrm{T}_{1}(5 \mathrm{~g} /$ día de Roughage mate) con 2.75 , seguidas de $\mathrm{T}_{2}(5 \mathrm{~g}$ de Roughage mate) con 2.73 y $_{0}$ (Testigo) con 2.73 , comparando estos re- sultados con la citada por el Instituto Babcock (1996) como Calificación de Condición Corporal promedio de 2.25 para terneras de entre 3 a 6 meses de edad, existiendo mayor incremento en las terneras de este ensayo. Es decir, se reportó un aumento de la Condición Corporal en todas las terneras del presente ensayo, debido al suplemento con fuentes energéticas y proteicas.

Tabla 6. Calificación de la Condición Corporal promedio por tratamiento para la evaluación de dos aditivos en terneras Holstein-Friesian.

\begin{tabular}{|c|c|}
\hline Tratamientos & Calificación de Condición Corporal \\
\hline T0(Testigo) & 2.73 \\
\hline T1 (5g de Roughage mate) & 2.75 \\
\hline $\mathrm{T} 2(2 \mathrm{~g}$ de 3 nitro- 20$)$ & 2.73 \\
\hline
\end{tabular}

\section{Conclusiones}

Los resultados de este trabajo sugieren que la mayor ganancia de peso se obtuvo con la suplementación de $\mathrm{T}_{2}$ (3 Nitro-20 3g/ternera/día) + Forraje $(0,75 \mathrm{~kg} /$ ternera $/$ día $),+$ Balanceado $(0,75 \mathrm{~kg}$ /ternera/día) + jabón cálcico (25 g/ternera/día), + sales minerales (50 g/ternera/día) y levadura $(15 \mathrm{~g} /$ ternera/día); con el cual se alcanzó, un incremento de peso vivo de $0.80 \mathrm{~kg} /$ ternera /día y una condición corporal de 2.73 que se califica como buena, lo cual implicará en el futuro productivo y reproductivo de las terneras.

La suplementación con $\mathrm{T}_{2}$ (3 Nitro-20 3 g/ternera/día) permite que las terneras lleguen a una me- nor edad (17 meses) y con el peso apropiado (400 $\mathrm{kg}$ de peso vivo) a la primera monta o inseminación, lo cual se traduce en una mayor vida productiva de las hembras. Sin embargo, es preciso señalar $\mathrm{T}_{1}$ (roughage mate $5 \mathrm{~g} /$ ternera/día) es el más rentable de los tratamientos. En este sentido, cabe indicar que el peso de las terneras a la primera monta de $400 \mathrm{~kg}$, la obtendrán a los 19 meses de edad y el primer parto a los 28 meses, por lo que el ganadero debe decidir, en función de sus requerimientos y presupuesto, cuál de estos dos sistemas de alimentación le conviene.

Para futuras investigaciones se recomienda incorporar nuevas variables como clima y época del año garantizando así la transferencia de tecnología a productores y generadores de políticas públicas. 


\section{Referencias}

Amaury, C. (2011). Uso de cultivos de levadura en la nutrición de rumiantes.

Andrade, L., \& León, V. (2013). Evaluación de aditivos en el crecimiento y condición corporal en vaconas medias Holstein Friesian. Tumbaco, Pichincha. Tesis de grado previo a la obtención del Título de Ingeniero Agrónomo, Universidad Central del Ecuador, Quito. Disponible en: http:// www.dspace.uce.edu.ec/bitstream/25000/1374/1/ T-UCE-0004-27.pdf

Araque C., \& Escalona M. (1995). Una nota sobre el uso de los bloques Multinutricionales en ganado de ceba.

Church, D., \& Pond, W. (1987). Fundamentos de nutrición y alimentación de animales. (Luis Jorge Pérez, Trad). México: Limusa.

Hillman, V.H., \& Wells, J.E. (2005) Lowew Digestivety Microbiology In Encyclopedia of Animal Science. New York: Department of Agriculture.
Grijalva, J. (1992). Crianza de terneras de leche. Instituto Nacional de Investigaciones Agropecuarias. Quito, EC. Boletín Técnico no 8. p. 3-14.

Instituto Babcok, Madison (USA). (1996). Para la investigación y desarrollo internacional de la industria lechera, Guías Técnicas Lecheras y las Esenciales Lecheras.

Moromenacho, M. León, V. (2007). Evaluación de la suplementación con tres niveles energéticos en la alimentación de terneras Holstein Friesian de 3 a 6 meses de edad. Alóag, Pichincha. Tesis para obtener el título de Ingeniero Agrónomo. Universidad Central del Ecuador, Quito.

Rodríguez, D. (2012). Levadura de cerveza como alternativa en nutrición animal. Cuenca: Universidad de Cuenca. 